\title{
A (IR)RACIONALIDADE NA DECISÃO DE SELECÇÃO DE PESSOAL
}

\section{Teresa Proença ${ }^{1}$}

Resumo: Este artigo apresenta uma reflexão conceptual sobre o processo de selecção de pessoal, centrando-se nos elementos irracionais que lhe estão subjacentes. Argumenta-se que o tradicional modelo normativo-preditivo de selecção de pessoal, assente numa racionalidade positivista visando a decisão óptima, traduzido pela escolha da "pessoa certa para o lugar certo", não é suficiente para compreender o modo como este processo decorre. Os desafios a este modelo relacionam-se com a crescente complexidade das características do trabalho, bem como com as lógicas cognitivas mobilizadas, que tornam a decisão mais incerta e complexa. Propõe-se um modelo baseado numa racionalidade de acção e fazendo uso de lógicas implícitas ou intuitivas, como alternativa à compreensão do processo de selecção de pessoal.

Palavras-chave: selecção de pessoal, irracionalidade, acção, intuição.

The (ir)rationality of the personnel selection decision-making process (Abstract): This paper examines personnel selection's practices and process, focusing on their somehow irrational elements. We argue that the traditional model in personnel selection, based upon normative and predictive assumptions in order to achieve the "one best" decision, is not enough to understand and describe personnel selection. The challenges to this model come from the growing complexity, unpredictability and ambiguity of the job demands, and of the cognitive processes used to make a decision. We propose a model based upon action rationality and an intuitive or implicit logic as an alternative approach to understand selection processes.

Key-words: selection decision, irrationality, action, intuition.

\section{Introdução}

Escolher o "melhor" ou o candidato "certo" para ocupar uma função é uma tarefa difícil que pode ser decepcionante. Newell e Shackleton (2002) argumentam que o sucesso no desempenho de uma função raramente depen-

\footnotetext{
${ }^{1}$ Faculdade de Economia da Universidade do Porto, Porto.

PSICOLOGIA, Vol. XXI (2), 2007, Edições Colibri, Lisboa, pp. 161-182.
} 
de só do indivíduo em particular. A função individual enquadra-se numa complexa rede de estruturas, processos e relações, que interagem com as acções do empregado. Por esta razão, os recrutados pouco competentes podem desempenhar positivamente a sua função se expostos a um contexto benigno e apoiante.

Esta perspectiva desafia o modelo tradicional da selecção de pessoal, que enfatiza um conjunto de regras e normas estruturadas assentes na medição, previsão e controlo. Neste artigo, argumentamos que o papel da racionalidade na decisão de selecção de pessoal, enquadrado num paradigma normativo-preditivo, não parece ser suficiente para compreender o processo de decisão. Existe ampla evidência da irracionalidade do processo de decisão segundo os padrões de racionalidade referidos.

Começamos por explicar os pressupostos do modelo normativo-preditivo da selecção de pessoal, enquadrando-os na tradição da Organização Científica do Trabalho e no desenvolvimento da Psicometria. Seguidamente, apresentamos os diferentes elementos que desafiam os pressupostos de objectividade do referido modelo: as mudanças na natureza do trabalho, o argumento da racionalidade limitada e da selectividade da percepção e o uso do conhecimento tácito ou intuitivo resultante da experiência mais ou menos ampla do decisor, em contextos semelhantes. Finalmente, apresenta-se a decisão de selecção numa perspectiva de acção, cujo sucesso depende mais da motivação e do envolvimento do decisor do que da racionalidade da decisão por si só.

\section{O modelo normativo-preditivo da selecção de pessoal}

A abordagem tradicional da selecção de pessoal centra-se na procura de instrumentos capazes de medir e de prever as características dos candidatos necessárias para o sucesso numa determinada função. O principal préssuposto é a possibilidade de identificar "a pessoa certa para o lugar certo".

Os principais referenciais teóricos e metodológicos da selecção são marcadamente tributários dos princípios epistemológicos positivistas, dada a ênfase na quantificação, na previsão e controlo dos acontecimentos, neste caso, a previsão do desempenho no trabalho e a adequação da pessoa à função (Wanous, 1992). Os avanços na psicometria, iniciados no século XX, aliados à preocupação em cientificar os princípios e práticas da gestão, iniciados por Taylor, transformaram a selecção de pessoal numa actividade mais objectiva e sistemática.

\section{A cientificidade do trabalho}

As principais preocupações de previsão na selecção de pessoal reflectem o desenvolvimento do modelo de organização do trabalho taylorista, as- 
sente na ultra-especialização e simplificação do trabalho. O desenvolvimento dos princípios da organização científica do trabalho culminaram no sistema de produção em massa, o fordismo, cujos ganhos de eficiência eram obtidos pela segmentação e rotinização de tarefas, num contexto de estabilidade do mercado e estabilidade da tecnologia.

Neste contexto, surgem metodologias científicas orientadas para a maximização dos resultados nos processos de selecção. Ou seja, métodos adequados ao matching entre os atributos dos candidatos e as características específicas da função, dando corpo aos princípios de Taylor the one best way e the right man in the right place (person-job fit). Estas práticas, ainda actuais, visavam encontrar e treinar indivíduos capazes de realizar tarefas altamente especializadas e pouco qualificados. Durante a vigência do taylorismo, a polivalência foi duramente censurada, por constituir uma ameaça aos pressupostos utilitários da organização do trabalho. Com sistemas de recompensas assentes no pressuposto limitado do homo øeconomicus, esta organização racional do trabalho foi bem-sucedida no controlo dos trabalhadores através da forte diferenciação entre os mesmos e originou um modelo de sistema produtivo caracterizado pela inflexibilidade da força de trabalho (Womack, Jones \& Roots, 1990).

A estabilidade do sistema produtivo e a intenção de previsibilidade implicou também o desenvolvimento de estudos de tempos e movimentos, que evoluíram posteriormente para práticas de análise do trabalho (job analysis). Trata-se de um exercício de recolha e descrição sistemática de informação sobre as tarefas executadas no âmbito de funções específicas. A medição dos métodos e tempos e a fragmentação do trabalho, iniciados por Taylor e Gilbreth, são a base da análise do trabalho (Townley, 1994), permitindo chegar à definição impessoal ou objectiva das funções. Obtêm-se dados associados à função, compatíveis com os objectivos de normalização e categorização das acções e gestos comuns a todos os postos de trabalho, frequentemente associados a componentes numéricas, nomeadamente requisitos de tempo e graus de importância.

A análise do trabalho tem várias utilizações, entre as quais o apoio aos procedimentos de selecção. No início da década de 20, Freyd (1923) reconheceu a importância da análise do trabalho para a selecção de pessoal e Algera e Greuter (1993, cit. p. Visser, Altink \& Algera, 1997) sustentam a sua actualidade e relevância. As suas aplicações são diversas: pode ser utilizada como base para um anúncio de emprego; fornece informação sobre o conteúdo e o contexto de trabalho ao candidato; permite formular um perfil de necêssidades e fazer inferências acerca dos instrumentos de selecção (preditores) a escolher. Uma das principais utilizações desta técnica é a de assegurar a universalidade de procedimentos e, desse modo, reduzir a probabilidade do impacto adverso das decisões de selecção em grupos minoritários. Nos EUA, 
país onde esta questão tem sido muito debatida (Arvey \& Faley, 1993; Greuter \& Algera, 1989), a técnica de análise de trabalho é utilizada para salvaguardar a legalidade dos procedimentos e decisões de selecção.

\section{O desenvolvimento da psicometria e a validade dos instrumentos de} selecção

A psicometria consiste na avaliação e medição das características psicológicas do indivíduo, ficando o seu desenvolvimento marcado pelas duas Grandes Guerras. Nessa altura, a sua aplicação centrava-se na mobilização e colocação de um grande número de militares, com pouco tempo de formação. Durante a $1 .{ }^{\text {a }}$ Guerra Mundial foram aplicados testes de inteligência a quase dois milhões de soldados-recrutas nos E.U.A., com o objectivo de seleccionar os mais competentes para as posições de maior responsabilidade (Rose, 1990). Outra das suas principais utilizações, sobretudo na fase do pós-guerra e devido à expansão do mercado de trabalho, decorreu em contexto organizacional, quer para a selecção de cargos de chefias, como para outros menos qualificados. As técnicas psicométricas medem e quantificam atributos individuais, o que lhes confere, pelo menos, a aparência de objectividade e lhes assegura credibilidade científica, na sua aplicação à gestão das pessoas.

Numa tentativa de prever o futuro da avaliação psicológica, Matarazzo (1992) sustenta que a avaliação da inteligência pelas medidas tradicionais continuará a ter uma utilização alargada. Como consequência do desenvolvimento recente dos conhecimentos na psicologia cognitiva, poderão surgir medidas relativas a estratégias e a processos cognitivos. Quanto à avaliação da personalidade, Matarazzo (1992) concorda com o incremento de testes genéricos sobre a estrutura da personalidade, na linha do inventário de personalidade NEO, desenvolvido por Costa e McCrae (1988). Ribeiro (1996) refere a realização de estudos de tradução e adaptação destes inventários à cultura portuguesa.

As decisões de selecção baseiam-se, ainda, na utilização de outros instrumentos, como o curriculum vitae, as entrevistas, os centros de avaliação e os testes situacionais, para além dos testes psicológicos mais vocacionados para a avaliação das aptidões e da personalidade.

Todos estes instrumentos são utilizados na expectativa de serem bons preditores do sucesso do indivíduo na função a que se candidata. Uma das principais preocupações da investigação neste domínio tem sido, justamente, a validade preditiva dos instrumentos referidos. A validade preditiva consiste no grau de confiança estatística com que esses instrumentos prevêem o desempenho futuro do candidato na função. Em termos sintéticos, trata-se de estabelecer as correlações entre os resultados obtidos nesses ins- 
trumentos (preditores) e na avaliação de um comportamento posterior do sujeito, já no desempenho da função para a qual foi seleccionado (critério). O critério pode assumir um valor mais ou menos objectivo, como a quantidade produzida, a avaliação do desempenho, a opinião da chefia, etc.

O modelo normativo-preditivo de selecção

Com base nos pressupostos desenvolvidos nos pontos anteriores, pode sistematizar-se o modelo tradicional de selecção, de acordo com os diferentes passos representados na figura 1 .

Figura 1 -Paradigma preditivo

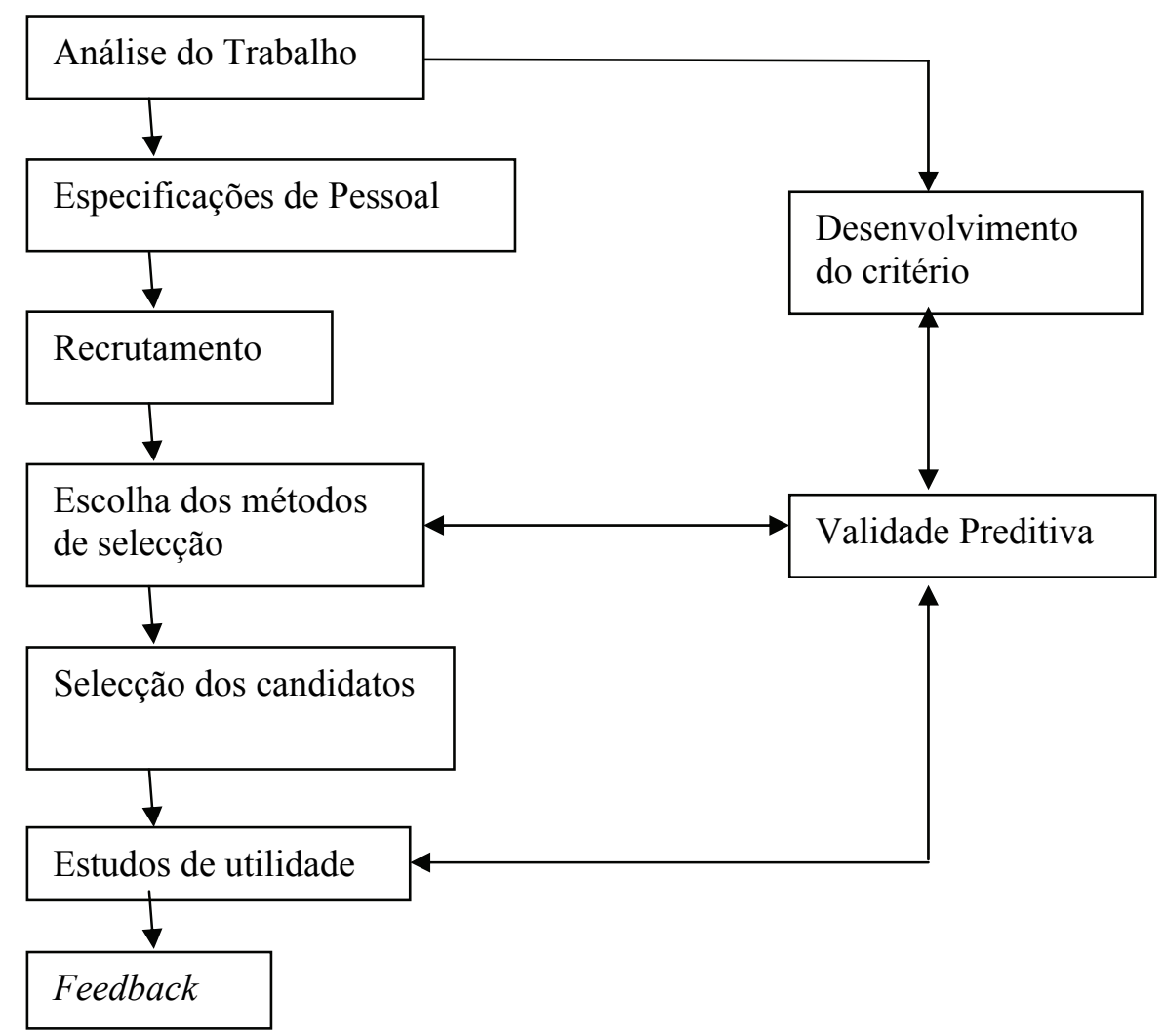

Fonte: adapt. Smith and Robertson, 1993. 
Segundo o paradigma ${ }^{2}$ normativo-preditivo, o processo de tomada de decisão deve ser racional. A literatura a-propósito prescreve o modo como as decisões de selecção devem ser tomadas e os requisitos para serem consideradas racionais. Assim, devem seguir uma série de passos sequenciais: 1) Perceber a situação e identificar o problema - isto é, analisar a necessidade de recrutamento e proceder à análise do trabalho; 2) Reunir informação sobre as aptidões, os conhecimentos e os comportamentos necessários à função - especificação de pessoal; 3) Gerar soluções possíveis para o problema - recrutamento; 4) Avaliar sistematicamente cada solução com base em instrumentos preditivos; 5) Escolher a "melhor" solução - selecção; 6) Monitorar e avaliar os resultados - estudos de validação e utilidade.

\section{A irracionalidade no processo de decisão de selecção?}

Existe numerosa evidência empírica que sugere o afastamento do prócesso de decisão de selecção em relação ao ideal prescrito pelo modelo normativo-preditivo.

Smith e Abrahamsen (1992, cit. p. Anderson \& Herriot, 1997) agruparam resultados de um inquérito relativo ao uso dos instrumentos preditivos em seis países: França, Alemanha, Israel, Holanda, Noruega e Reino Unido. Nesses países, as entrevistas e as folhas de candidatura (ou curriculum) eram as técnicas de selecção mais utilizadas, aparecendo em mais de $84 \%$ dos processos, enquanto os testes psicométricos (de personalidade e cognitivos) eram usados em 10 a $20 \%$ das vagas e os centros de avaliação os mais raramente utilizados. Por outro lado, apesar de os instrumentos de avaliação terem uma utilização bastante alargada, a prática não reflecte os resultados da investigação já realizada (Anderson \& Herriot, 1997). Ou seja, os instrumentos mais utilizados pelos profissionais não são necessariamente aqueles cuja investigação demonstrou maior validade. A correlação entre a frequência de utilização dos instrumentos e a sua validade é negativa e igual a - 0,25 (Smith \& Abrahamsen, 1992, cit. p. Anderson \& Herriot, 1997). Também nos Estados Unidos, Muchinsky (1994, cit. p. Anderson \& Herriot, 1997) constatou a baixa frequência de utilização dos instrumentos mais válidos e, em Portugal, Ribeiro (1996) conclui que os responsáveis pela selecção tendem a utilizar mais frequentemente os métodos com menor validade.

\footnotetext{
2 O termo paradigma é utilizado segundo a significação de Khun (1962): um modo de ver o mundo que pressupõe um conjunto de teorias e metodologias de ciência, num dado período da história.
} 
Existe ainda numerosa investigação que ilustra a existência de decisões irracionais, quando comparadas com os padrões normativos (Cyert \& March, 1963; Lindblom, 1959; March \& Olsen, 1976; Nisbett \& Ross, 1980; Tversky \& Kahneman, 1974). As aparentes irracionalidades não se limitam a decisões insignificantes, as pessoas comportam-se de modo idêntico quando se trata de questões estratégicas, e não estão limitadas aos indivíduos, pois também acontecem nos grupos (Janis, 1972).

A maior parte dos estudos neste domínio centram-se num modelo quantitativo e normativo, na tentativa de evitar o erro cognitivo. O conceito de erro (bias) cognitivo é definido como uma predisposição injustificada para um candidato ou para os seus atributos, possuindo uma componente irracional, quando baseada nas emoções, e que impede o seleccionador de avaliar objectivamente o candidato. Na literatura sobre selecção, aparece frequentemente o termo erro associado à utilização de critérios e procedimentos não estandardizados, não estruturados, nem objectivos, como o caso da entrevista (Dipboye, 1994; Dipboye \& Gaugler, 1993). Assim, a predisposição do seleccionador para determinadas características do candidato torna-se um resultado auto-realizador dos procedimentos utilizados, em vez de reflectir as qualificações e traços objectivos do candidato.

Anderson e Shackleton (1993), baseando-se nos estudos de Macan e Dipboye (1988), de Postman, Bruner e McGinnies, (1948), de Wareing e Stockdale (1987) e de Webster (1964), categorizaram os seguintes erros: o efeito das expectativas, o erro da confirmação na procura de informação, o efeito de primazia, os estereótipos e protótipos, o efeito de halo, o efeito de contraste, o erro da informação negativa, o efeito da auto-identificação (similar-to-me), o erro dos gostos pessoais, a atenção selectiva e a sobrecarga de informação, o erro da atribuição fundamental e a defesa perceptiva.

Para uma compreensão mais aprofundada do processo de selecção de pessoal, é necessário abordar os factores responsáveis pelo afastamento em relação ao modelo tradicional referido.

Um dos desafios à racionalidade vigente relaciona-se com as alterações dos modelos de organização do trabalho, e com a actual complexidade da natureza do trabalho, resultantes de um contexto de crescente competitividade dos mercados e da globalização da economia. É já relativamente consensual, mesmo entre os defensores do modelo tradicional de selecção, a ideia de que o paradigma preditivo é limitativo para certos tipos de funções, como, por exemplo, as que requerem elevados níveis de interdependência (Ribeiro, 1996).

Outro dos desafios refere-se ao enquadramento da selecção enquanto processo de decisão. Assim, encontra-se sujeito aos limites da racionalidade, resultantes das características cognitivas do indivíduo ou de questões de poder nas organizações. 
As mudanças na natureza do trabalho

Os modelos de organização pós-burocráticos implicam uma mudança no que diz respeito aos critérios habitualmente utilizados na selecção de pessoal. A natureza do trabalho assume uma maior complexidade, as funções, as competências e as qualificações mudam rapidamente no tempo, pelo que os critérios de selecção baseados nas características específicas e estáveis de uma função deixam de ter significado. "Os seleccionadores são confrontados com decisões de selecção para trabalhos, que são menos claros, mudam rapidamente e cujo conhecimento a priori é difícil ou impossível de possuir" (Oliveira, 1998, p. 16). Howard (1995) fala do papel no trabalho (work role) em vez de função, para se referir a um conjunto de actividades e tarefas fluídas que acrescentam valor de modo novo, nomeadamente pela resolução de problemas e pela inovação. Guion (1997) considera que os constructos de adaptabilidade, rapidez de aprendizagem e inovação são fundamentais em ambientes e organizações sujeitas à mudança. Fletcher (1997) sugere a necessidade de avaliar a adaptabilidade dos colaboradores à requalificação e à polivalência para novos papéis de trabalho, tendo em conta os atributos dos candidatos que se relacionem com as exigências de mudança nos perfis das funções e da organização e com a própria cultura e clima organizacional.

Bowen, Ledford e Nathan (1991) propõem que, em vez da adequação da pessoa à função (person-job fit), a selecção das pessoas seja feita com base na adequação da pessoa à organização (person-organisation fit). $\mathrm{Ou}$ seja, torna-se necessária uma adequação mais ampla, incluindo os valores e as atitudes que ajudem a promover a eficácia da organização, bem como a possível experiência que o trabalhador obtém pela rotação e polivalência em diferentes funções ou departamentos da empresa. Os autores citados não sugerem eliminar os critérios tradicionais de adequação à função, mas, antes, incorporar outros critérios de medida que possam prever melhor o desempenho no trabalho a longo prazo, e em organizações sujeitas a imperativos de flexibilidade. Para Schneider (1994), a ideia da adequação da pessoa à organização implica que a análise tradicional do trabalho deixe de se restringir aos conhecimentos, aptidões e competências exigidos pelo trabalho, para se centrar mais nas atitudes, valores e personalidade relevantes para a organização, sempre de acordo com uma orientação para o futuro.

Como consequência destas ideias, os critérios ou instrumentos de medida utilizados deverão envolver todo o contexto organizacional, já que este tem um efeito mediador na relação entre as características individuais e a performance individual. Para Dipboye (1997), as entrevistas não estruturadas, por exemplo, podem funcionar como uma táctica preliminar de sociali- 
zação, ao serem utilizadas para alinhar as expectativas do candidato com a cultura da organização.

Segundo Schneider (1994), o tradicional paradigma da predição, bem como os estudos de validade preditiva dos instrumentos utilizados, necessitarão, assim, de ser repensados e remodelados. As variáveis de rendimento individual utilizadas como critérios nos estudos de validade preditiva tornam-se mais difíceis de operacionalizar, pois se, por um lado, as funções deixam de ter características específicas, por outro lado, estão cada vez mais exigentes, ao nível da colaboração das pessoas, existindo uma forte componente de interdependência recíproca (Ribeiro, 1996). Ao mesmo tempo, a estabilidade do trabalho que sustentava o valor dos estudos de validade preditiva, deixa de ser um dado. Que sentido faz a validação de um instrumento com um critério que fica ultrapassado rapidamente? Os estudos de validade concorrente podem tornar-se mais frequentes que os de validade preditiva, na medida em que não necessitam de dados longitudinais (Fletcher, 1997). Acrescente-se que a generalização dos dados de validação poderá ter pouco interesse para os práticos, na medida em que o valor que eles atribuem a essa informação vai depender, sobretudo, da sua adequação às especificidades e à situação das suas organizações empregadoras. Aliás, o desenho de validação do processo de selecção poderá fazer mais sentido se tiver como critério o desempenho ou eficácia da organização e não unicamente o desempenho ou rendimento individual.

A selecção como processo de tomada de decisão: as características cognitivas dos indivíduos e o poder como factores limitativos

Os modelos de racionalidade limitada surgiram como resposta às críticas dos modelos de racionalidade na tomada de decisão, oriundos da economia, e baseados em princípios hedonistas, utilitários ou calculistas, buscando soluções de optimização (Lord \& Maher, 1990). Numa perspectiva de racionalidade limitada, o indivíduo tem acesso a um conjunto reduzido de informação e possui capacidades cognitivas limitadas. Tal como nos modelos clássicos de racionalidade, a decisão é planeada, mas, ao contrário destes, o processamento da informação termina quando aparece a primeira alternativa aceitável e não óptima.

Os modelos cibernéticos, tais como os representados pelos trabalhos de Ashby (1956) e Wiener (1954), aplicados ao contexto organizacional, consideram que, ao contrário dos modelos racionais, não existe uma linearidade temporal no processamento de informação para a decisão e escolha. Estes modelos foram aplicados ao contexto organizacional em diversas áreas, tais como a resolução de problemas (Mintzberg, Raisinghani \& Theoret, 1976), as percepções sociais (Hastie \& Park, 1986) e a avaliação 
do desempenho (DeNisi \& Williams, 1988), fazendo sobressair o feedback como mecanismo que altera os processos cognitivos e a aprendizagem comportamental.

O processo de tomada de decisão nas organizações é analisado por Butler (1991), que toma em consideração aspectos da estrutura e contexto geral da organização. Este autor considera que a racionalidade no contexto organizacional exprime-se de diferentes formas, significativamente diferentes de concepções racionais. A dificuldade de atingir uma decisão ideal relaciona-se com as pressões para uma decisão atempada ou rápida, o que não é concordante com a procura exaustiva de informação.

A manutenção ou aquisição de poder por parte dos decisores é também uma variável para a compreensão do afastamento dos seleccionadores relativamente a decisões consideradas racionais. Segundo Pfeffer (1981), o afastamento em relação a procedimentos mais objectivos e estandardizados permite aos seleccionadores uma maior capacidade de influenciar a decisão, utilizando critérios ou informação que sustente as suas preferências. Para além disso, a monitorização do processo de selecção por entidades externas torna-se mais difícil. Refira-se ainda que critérios como "ser alguém conhecido" ou "a decisão da chefia superior é sempre mais importante" (Oliveira \& Proença, 2003) utilizados na decisão de selecção sugerem a manutenção dos valores e cultura da organização. A força da função cultural de muitas práticas organizacionais pode levá-las a persistir, mesmo com sinais pouco evidentes de que as mesmas contribuam, de modo eficaz, para os objectivos manifestos da organização (Dipboye, 1997).

No domínio da psicologia da percepção e mais recentemente da psicologia sócio-cognitiva, é abundante a literatura que retrata a impossibilidade de o indivíduo processar toda a informação proveniente do ambiente, caracterizando o processo perceptivo como eminentemente subjectivo. $\mathrm{O}$ indivíduo é comparado a um cientista ingénuo (Asch, 1946) ou a um cognitivo avarento (Nisbett \& Ross, 1980). No primeiro caso, o indivíduo é alguém que procura explicações ou teorias para os comportamentos das pessoas, sem recorrer à experimentação, mas, antes, a informação significativa e organizada em categorias ou esquemas que tem disponível, ou seja, às suas teorias implícitas. O termo implícito, segundo Leyens (1983), é no sentido de o indivíduo não ser capaz de as expor de modo formal, de não possuírem qualquer critério objectivo de validade, não significando, porém, que sejam totalmente inconscientes. No segundo caso, o indivíduo, para realizar menos esforço, baseia-se em heurísticas ou atalhos que lhe permitem raciocínios mais rápidos. Este tipo de funcionamento pode causar problemas, na medida em que supõe, por vezes, generalizações abusivas, como os estereótipos, originando julgamentos discriminatórios relativamente a gru- 
pos de pessoas em relação aos quais existem crenças generalizadas ou determinados erros perceptivos, analisados anteriormente.

Porém, Oliveira (1998) salienta que o termo "erro" deverá ser utilizado com cuidado, pois pode ser o comportamento correcto para a empresa em causa. Isto é, o seleccionador, devido à sua experiência e ao conhecimento dos atributos que são importantes numa determinada empresa, pode rejeitar determinados resultados objectivos obtidos em testes, em favor da informação mais subjectiva que obtém, por exemplo, no contacto pessoal na entrevista. Werninont e Campbell (1968) distinguiram entre "sinais" - comportamentos simples, como evitar o contacto ocular num dado momento - e "amostras" - conjuntos de características similares do candidato -, afirmando que os primeiros são um potencial "erro" na previsão do desempenho futuro, pois são bastante mais subjectivos, por se basearem em comportamentos isolados sem reconhecimento da sua consistência. De acordo com Anderson e Shackleton (1993), o uso de sinais para prever o desempenho no trabalho não parece estar a diminuir. Outros autores (Guion, 1965; Robertson \& Smith, 1993) consideram que a utilização destes sinais são importantes na avaliação em selecção, como, por exemplo, se existem dados contraditórios ou quando é necessária a compreensão das características subjectivas ou idiossincráticas do candidato. Aliás, no contexto de mudança dos papéis de trabalho, os seleccionadores podem estar mais interessados em procurar sinais sobre, por exemplo, o potencial criativo ou de iniciativa do indivíduo, que podem não ser identificáveis em amostras, nem noutro tipo de procedimentos estruturados e estandardizados.

Assim, torna-se importante uma análise mais detalhada sobre o modo como os seleccionadores fazem a ligação entre as suas próprias cognições e o modo como integram as necessidades objectivas da organização e as variáveis subjectivas dos candidatos.

\section{O modelo da aç̧ão-intuição na selecção de pessoal}

As limitações ao modelo normativo-preditivo encontradas na literatura sugerem dois tipos de argumentos na descrição do processo de selecção. Primeiro, enquanto processo sócio-cognitivo para a elaboração de um julgamento, a decisão de seleccionar um candidato envolve o processamento de informação social e a utilização de lógicas tácitas ou intuitivas, com características inconscientes ou pré-conscientes, mas não necessariamente irracionais. Em segundo lugar, a decisão de selecção pode ser considerada como um dos passos de um processo mais vasto orientado para a acção, cujo sucesso depende de critérios, por vezes, incompatíveis com decisões racionais. 
O processamento de informação social e o papel de lógicas tácitas ou intuitivas

A selecção é um processo sócio-cognitivo, de recolha e processamento de informação dos candidatos (Millar, Crute \& Hargie, 1993), no sentido em que se procura identificar os atributos dos indivíduos considerados relevantes para a função ou para a organização, existindo, por isso, um determinado racional ou lógica subjacente. Para gerir o processamento da informação recebida, o indivíduo possui uma série de estratégias, das quais salientamos as noções de categorização, de esquema - schema - e de guião - script. Quer o esquema, quer o guião são categorizações interiorizadas, ou estruturas conceptuais, através das quais os indivíduos atribuem significado às informações que constituem as suas experiências de vida. Estes esquemas permitem ao indivíduo compreender a complexidade da vida social e economizar esforço no processamento de informação.

Já no início da década de 30, Bartlet (1932) apresentava o conceito de esquema como "experiência organizada", cuja formação decorria de forma dinâmica - esquematização (schemata) -, pela organização de nova informação em relação a esquemas já armazenados em memória, segundo uma lógica consistente. Esta lógica de organização não era desprovida de uma componente emocional, pelo contrário, podia ser uma condição necessária para atribuir ou reconhecer o significado da informação recebida.

Investigação recente neste domínio mostra que as pessoas recordam mais facilmente informação organizada por temas (Augoustinos \& Walker, 1995; Baddeley, 1990), e que muitas das nossas opiniões e decisões diárias ocorrem com pouca deliberação. Mandler (1989) considera ainda que, a maioria das vezes, os esquemas são utilizados de modo automático, dando sentido aos estímulos recebidos.

Apesar das limitações que estas estruturas conceptuais implicam, elas são funcionais e permitem o nosso bem-estar. Para além disso, o processo de organização de informação é contínuo, podendo haver renovação e reavaliação das estruturas conceptuais. Segundo Bartlet (1932), o processo de organização da informação é dinâmico, com características intencionais, sociais e afectivas, sendo que os esquemas são continuamente modificados, pelo que a avaliação do conhecimento anterior é constante, não se podendo chegar a falar em desactualização. Estas estruturas de conhecimento são utilizadas em situações sociais e permitem-nos lidar com as nossas limitações cognitivas.

O processo de organização da informação e elaboração de julgamento pode ocorrer pela utilização de lógicas tácitas ou intuitivas. Tratar-se-iam de lógicas não expressáveis resultantes da experiência ou da rotinização de procedimentos. De acordo com Day e Lord (1992), a lógica utilizada na 
selecção tende a ser menos consciente ou expressável, para seleccionadores mais experientes.

A intuição é um constructo complexo, com múltiplas dimensões e, muitas vezes, associado ao conhecimento implícito. A tabela 1 resume as diferentes contribuições para a compreensão da intuição e conhecimento implícito.

Tabela 1-As características da intuição e do conhecimento implícito, segundo diversos autores

\begin{tabular}{ll}
\hline $\begin{array}{l}\text { Bartlet (1932) } \\
\text { Wittgenstein (1980, 1982) }\end{array}$ & $\begin{array}{l}\text { Intuição: processo iterativo de atribuição de signi- } \\
\text { ficado, implícito ou inato, envolvendo a emoção }\end{array}$ \\
\hline Polany (1958, 1962) & $\begin{array}{l}\text { Conhecimento implícito: conhecimento processual } \\
\text { ou tácito baseado na experiência e possuindo vá- } \\
\text { rios graus de consciência }\end{array}$ \\
\hline Cooley (1987) & $\begin{array}{l}\text { Conhecimento implícito: conhecimento subjectivo } \\
\text { orientado para a acção, resultante da experiência, } \\
\text { i.é, aprender-fazendo }\end{array}$ \\
\hline
\end{tabular}

Matte-Blanco $(1975,1988)$ Intuição: processo inconsciente e lógico, que envolve a organização de esquemas de experiência prévios, armazenados na memória

\begin{tabular}{ll}
\hline Agor (1986, 1989) & $\begin{array}{l}\text { Intuição: competência individual, que pode ser de- } \\
\text { senvolvida pelo treino }\end{array}$ \\
\hline Behling \& Eckel (1989) & $\begin{array}{l}\text { Seis conceptualizações de intuição: (1) um poder } \\
\text { paranormal ou um sexto sentido; (2) um traço de } \\
\text { personalidade; (3) um processo inconsciente; (4) } \\
\text { um conjunto de acções; (5) experiência individual; } \\
\text { (6) raciocínio implícito. }\end{array}$ \\
\hline Clement (1994) & $\begin{array}{l}\text { Intuition is a broader construct than implicit know- } \\
\text { ledge, which involves two dimensions: implicit } \\
\text { and explicit. }\end{array}$ \\
\hline Crossan et al. (1999) & $\begin{array}{l}\text { Intuition as a two-dimensional construct: expert in- } \\
\text { tuition (pattern recognition, past-oriented, exploi- } \\
\text { tation) and entrepreneurial intuition (novel connec- } \\
\text { tions, future oriented, and exploration). }\end{array}$ \\
\hline
\end{tabular}


No processo de selecção, os conceitos de intuição e de conhecimento implícito podem ser especialmente relevantes na explicação do processo de tomada de decisão, nomeadamente, quando o seleccionador tem de decidir a favor ou contra um candidato. A maioria das contribuições sobre conhecimento implícito e intuição concordam que o seu uso é inconsciente e baseado na experiência passada do indivíduo, sem uma total consciência de como o processo decorre. Particularmente relevante é o conceito de inconsciente lógico (Matte-Blanco, 1975, 1988), que pressupõe um determinado racional $^{3}$ no processo inconsciente de armazenamento da informação. Este racional refere-se a um conjunto inter-relacionado de categorias de conhecimento e de experiência, utilizado quase instantaneamente, evitando o caos na nossa vida diária pelo uso de informação não organizada. Na mesma linha, Wittgenstein (1980) sugere o conceito de ponto fulcral (i.e., o momento em que os gestores chegam a um julgamento definitivo, confirmando ou refutando o processo de adequação de um candidato à função, como resultado de um processo de intuição iterativo e sequencial. Adicionalmente, a intuição pode ser usada "num flash", mas, subjacente, existe uma compreensão pré-consciente dos atributos dos candidatos. Assim, a intuição é crucial para o julgamento definitivo.

Para Oliveira (1989) e Cooley (1987), o conhecimento baseado em regras implícitas, ou conhecimento tácito, está presente no processo de selecção, quando estão em causa procedimentos mais iterativos (como a entrevista), ou quando, face a informação menos estruturada, o responsável da selecção sabe implicitamente que critérios utilizar para alcançar um resultado efectivo. Proença e Oliveira (2005) alargam o âmbito das conclusões anteriores, sugerindo que a influência de regras implícitas no processo de selecção não se restringe ao julgamento efectuado a partir de dados subjectivos em procedimentos não estruturados. A utilização destas regras parece ocorrer desde que o responsável da selecção, deparando com a tarefa de ter de hierarquizar curriculum - informação estruturada -, se veja impossibilitado de utilizar regras explícitas, pelo facto de os principais elementos normativos - classificações literárias e níveis de qualificação ou literários serem iguais nos diferentes casos, utilizando, para isso, outras "regras menos científicas", mas a que o indivíduo atribui valor.

\footnotetext{
${ }^{3}$ Freud apenas atribui ao nosso inconsciente o papel de reservatório das nossas forças motoras, desejos e emoções e não o considera como uma instância lógica de conhecimento.
} 
Figura 2 - A influência das regras tácitas e implícitas no processo de selecção

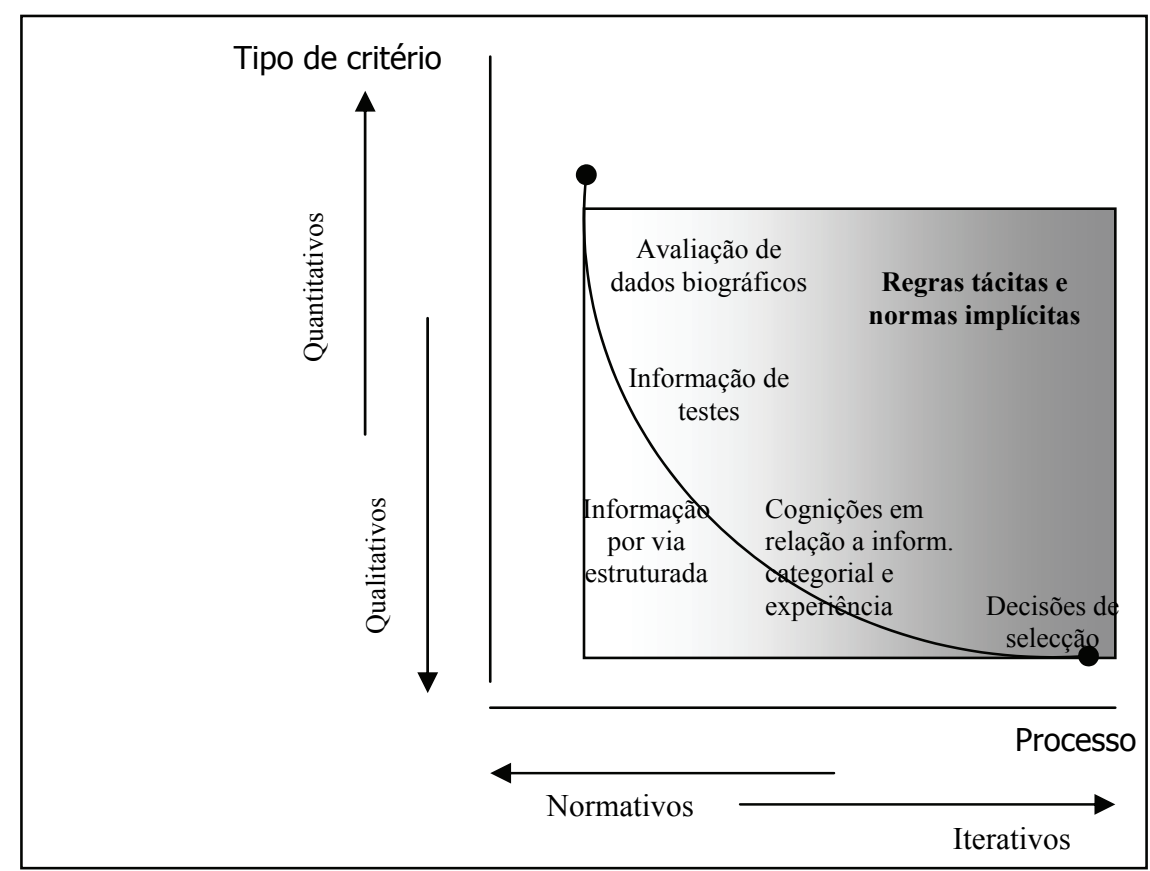

Fonte: Adaptado de Cooley (1987)

$\mathrm{Na}$ figura 2, está representado um modelo do processo de tomada de decisão em contexto de selecção, que sugere a utilização do conhecimento implícito ou tácito, sobretudo face a dados qualitativos e num processo iterativo. Este modelo é adaptado do modelo de Cooley (1987), que apresenta uma área tácita e implícita mais restrita, não articulável perante, por exemplo, informação biográfica e de teste mais estruturada. O modelo apresentado pretende salientar que o conhecimento implícito poderá ser utilizado pelo responsável da selecção, em qualquer momento do processo de selecção, sempre que o conhecimento normativo e estruturado não permita progredir na decisão. Assim, a utilização de regras tácitas pode ocorrer, porque elas permitem chegar a uma melhor compreensão dos atributos do candidato. Também não é evidente que esta opção seja menos racional, mas, antes, pode apresentar-se como a única opção dos seleccionadores obterem as respostas que necessitam, relativamente a qualidades de personalidade imprécisas e aparentemente intangíveis, de importância para as organizações, como a criatividade, a irreverência ou a persistência. 


\section{A orientação para a acção}

O paradigma normativo-preditivo assume como crucial a questão da decisão de selecção. O mais importante é seleccionar a pessoa "certa" que resolverá o problema identificado, porque será capaz de levar a cabo com sucesso as tarefas específicas da função para a qual foi seleccionada. Porém, esta ideia ignora o facto de o sucesso numa função raramente depender só do indivíduo em particular. Existe um conjunto de factores contextuais que interage com as acções em particular do recruta. Um recruta potencialmente muito competente pode ser muito malsucedido por uma multiplicidade de acontecimentos: recursos pouco adequados, treino reduzido, um supervisor ou colegas pouco apoiantes, etc. Ou seja, a decisão de 'escolher a pessoa "certa", per si, não parece muito adequada, sem considerar os acontecimentos anteriores e posteriores à mesma. Brunsson (1982) argumenta que o paradigma normativo-preditivo não reconhece a decisão como um meio ou um passo de uma acção mais vasta, mas como um fim em si próprio. Para além disso, sublinha a ideia de que as decisões racionais nem sempre são boas bases para acções apropriadas e bemsucedidas: "Quando o processo de decisão tem como meta a acção, as normas de racionalidade não deveriam ser só critérios internos à própria decisão; deveriam adaptar-se aos critérios externos da acção" (p. 32). A decisão de selecção pode, assim, ser encarada como um episódio na integração do indivíduo na organização. E a integração será bem sucedida quando existirem expectativas, motivação e compromisso positivos de ambos os lados. Alguns autores (Brunson, 1982; Lindblom, 1959; Newell \& Shackleton, 2002) avançam algumas ideias que permitem apontar uma oposição entre racionalidade da acção e racionalidade da decisão (Tabela 2).

Tabela 2 - A oposição entre racionalidade da acção e racionalidade da decisão

\begin{tabular}{ll}
\hline Racionalidade da acção & Racionalidade da decisão \\
\hline Poucas alternativas & Múltiplas alternativas \\
$\begin{array}{l}\text { Análise das consequências positivas da } \\
\text { decisão }\end{array}$ & $\begin{array}{l}\text { Análise das consequências positivas e } \\
\text { negativas da decisão }\end{array}$ \\
Construir os objectivos a posteriori & Objectivos pré-definidos \\
\hline
\end{tabular}

Podemos apontar três grandes diferenças entre uma perspectiva de acção e uma perspectiva de decisão. Primeiro, uma perspectiva de acção considera que a existência de múltiplas alternativas gera incerteza, o que 
reduz o compromisso e a motivação. Se os decisores não estão certos acerca de um determinado curso de acção, terão mais dificuldade em assumi-lo e a comprometerem-se. Assim, é desejável considerar menos alternativas. Por oposição, numa perspectiva de decisão, ser incapaz de considerar múltiplas alternativas é descrito como uma deficiência ou limitação das capacidades cognitivas do decisor, como argumentámos anteriormente.

Em segundo lugar, uma racionalidade de acção sugere que pode ser mais sensato procurar as consequências positivas das poucas alternativas em questão, pois conhecê-las reduz a inconsistência que pode suscitar a dúvida. Ao contrário, numa racionalidade de decisão, deve procurar-se ambas as consequências positivas e negativas. Como a acção depende da convicção, compromisso e motivação do indivíduo, a intuição e os factores emocionais também podem ter um papel importante (Butler, 1991) e, por isso, pode tornar-se difícil mudar o curso de acção, mesmo quando ela se revela errada, como ilustra o fenómeno da escalada de decisão (Drummond, 2001).

Tabela 3 - Lógicas de acção-intuição no processo de selecção

\begin{tabular}{ll}
\hline $\begin{array}{l}\text { Elementos irracionais no processo } \\
\text { de seleç̧ão }\end{array}$ & Lógicas de acção-intuição \\
\hline Entrevistas não estruturadas & $\begin{array}{l}\text { Maior compromisso, motivação e capacidade } \\
\text { de influência; mais possibilidade de uso de } \\
\text { lógicas intuitivas e de heurísticas. }\end{array}$ \\
$\begin{array}{l}\text { Tomar decisões rapidamente com } \\
\text { base em poucas alternativas }\end{array}$ & $\begin{array}{l}\text { Maior compromisso, motivação, pressão para } \\
\text { a acção e maior mobilização de lógicas intui- } \\
\text { tivas. }\end{array}$ \\
$\begin{array}{l}\text { Referências ou contactos pessoais } \\
\text { Julgamento clínico }\end{array}$ & $\begin{array}{l}\text { Uso de lógicas intuitivas, teorias implícitas, } \\
\text { convicções, maior compromisso e motivação }\end{array}$ \\
$\begin{array}{l}\text { Não avaliar sistematicamente os } \\
\text { processos de selecção }\end{array}$ & $\begin{array}{l}\text { Confiança nas escolhas feitas para evitar dis- } \\
\text { sonância cognitiva e manter elevada a moti- } \\
\text { vação e o compromisso. }\end{array}$ \\
\hline
\end{tabular}

Finalmente, uma perspectiva de acção considera o processo de decisão como incremental e descontínuo, em vez de planeado e contínuo. Assim pode ser mais apropriado definir a estratégia a partir das consequências e inventar os objectivos a posteriori. Lindblom (1959) argumentou que uma 
análise racional extensiva é irrelevante para os passos incrementais na política nacional americana.

As lógicas observadas nos processos de decisão podem ser explicadas como racionalidade da acção, sobretudo em situações em que a motivação e o compromisso são altamente benéficos. No quadro 3, sintetizamos as diferentes explicações para alguns dos elementos irracionais da selecção, segundo o modelo normativo-preditivo.

\section{Conclusão}

Este trabalho apresentou uma reflexão conceptual sobre o processo de selecção de pessoal, centrando-se nos elementos (ir)racionais que lhe estão subjacentes.

Analisaram-se os pressupostos e as características do modelo normativo-preditivo da selecção de pessoal. A procura da "pessoa certa para o lugar certo" resume o foco central do modelo tradicional de selecção, cujos referenciais teóricos e metodológicos da selecção são marcadamente tributários dos princípios epistemológicos positivistas, dada a ênfase na quantificação das características individuais e na previsão do desempenho no trabalho. As metodologias de eleição caracterizam-se por um elevado grau de estruturação e objectivação, enquadradas num modelo sequencial segundo as regras racionais de tomada de decisão.

Contudo, existe evidência empírica que mostra o afastamento dos profissionais da selecção de pessoal em relação ao modelo anterior. Pela oposição à lógica positivista, tida como racional, este desvio é habitualmente considerado irracional. Ao longo deste artigo, realçaram-se os principais elementos responsáveis pelo afastamento em relação a regras objectivas e estruturadas. Por um lado, as condições de complexidade e instabilidade da actual natureza do trabalho tornam difícil a definição e a previsão da pessoa e do lugar "certos". Por outro lado, o argumento da racionalidade limitada, os erros perceptivos e o uso de lógicas tácitas e intuitivas tornam ambígua a escolha da "pessoa certa". O enquadramento da decisão de selecção numa perspectiva de acção, cujo sucesso depende mais da motivação e do envolvimento dos actores envolvidos no curso de acção escolhido, põe em causa a própria racionalidade da decisão por si só.

Como consequência da discussão encetada, sugere-se que o processo de selecção não seja tratado de forma maniqueísta pela ciência, segundo a qual todos os fenómenos que se afastam de uma racionalidade científica são considerados como irracionais e associados à nossa fraqueza intelectual, individual ou colectiva. Em vez disso, salienta-se que um modelo de acção-intuição parece ser mais adequado à descrição do processo de selecção, 
enquanto o modelo preditivo-normativo assume uma perspectiva mais préscritiva. A selecção, enquanto processo sócio-cognitivo, está sujeita a lógicas implícitas e intuitivas, mais mobilizáveis por seleccionadores com maior experiência. Estas facilitam o envolvimento dos decisores num dado curso de acção, o qual poderá ser um pressuposto mais decisivo no sucesso do candidato escolhido, do que a tarefa da previsão, cujas premissas se tornaram menos alcançáveis.

\section{Referências}

Agor W. (1986). The logic of intuition: how top executives make important decisions. Organizational Dynamics, Winter, 5-15.

Agor, W. (1989). Intuition in organizations. Newbury Park, CA: Sage.

Anderson, N. \& Herriot, P. (1997). Selecting for change: how will personnel and selection psychology survive? In N. Anderson \& P. Herriot (Eds.), International handbook of selection and assessment (pp. 1-38). England: Wiley.

Anderson, N. \& Shackleton, V. (1993). Successful selection interviewing. Oxford: Blackwell Publications.

Arvey, R. D. \& Faley, R. H. (1993). Fairness in selecting employees. $2^{\text {nd }}$ ed. Reading, MA: Addison-Wesley.

Asch, S. E. (1946). Forming impressions of personality. Journal of Abnormal and Social Psychology, 41, 258-290.

Augoustinos, M. \& Walker, I. (1995). Social cognition: an integrated introduction. London: Sage Publications.

Baddeley, A. (1990). Human memory: theory and practice. London: Lawrence Lae.

Bartlet, F. C. (1995). Remembering: a study in experimental and social psychology. Cambridge: Cambridge University Press.

Behling, O. \& Eckel, N. (1989). Making sense of intuition. Academy of Management Executive, 5, 377-385.

Bowen, D. E., Ledford, G. E. \& Nathan, B. R. (1991). Hiring for the organization not the job. Academy of Management Executive, 5, 35-51.

Brunsson, N. (1982). The irrationality of action and action rationality: decisions, ideologies and organizational actions. Journal of Management Studies, 19, 29-44 .

Butler, R. (1991). Designing organizations: a decision-making perspective. London: Routledge.

Clement, J. (1994). Use of physical intuition and imagistic simulation in expert problem solving. In D. Tirosh (Ed.), Implicit and explicit knowledge. An educational approach. NJ: Ablex Publishing Corporation.

Cooley, M. (1987). Architect or Bee? London: Hogarth.

Costa, P. T. \& Mc Crae, R. R. (1988). From catalog to classification: Murray's need's and the five-factor model. Journal of Personality and Social Psycho$\log y, 55,258-265$. 
Crossan, M. M., Lane, H. W. \& White, R. E. (1999). An organizational learning framework: from intuition to institution. Academy of Management Review, 24, 522-537.

Cyert, R. M. \& March, J. G. (1963). A Behavioural theory of the firm. Englewood Cliffs, NJ: Prentice-Hall.

Day, D. V. \& Lord, R. G. (1992). Expertise and problem categorization: the role of expert processing in organization sense-making. Journal of Management Studies, 29, 35-47.

DeNisi, A. S. \& Williams, K. J. (1988). Cognitive approaches to performance appraisal. In K. Rowland \& G. Ferris (Eds.), Research in personnel and human resource management. Greenwich, CT: Jai Press.

Dipboye, R. (1994). Structured and unstructured selection interviews: beyond the job-fit model. Research in personnel and human resource management, 12, 79-123 .

Dipboye, R. (1997). Structured selection interviews. In N. Anderson \& P. Herriot (Eds.), International handbook of selection and assessment (pp. 455-473). England: Wiley.

Dipboye, R. \& Gaugler, B. B. (1993). Cognitive and behavioral processes in the selection interview. In N. Schimdt (Ed.), Personnel selection in organizations. San Francisco: Jossey-Bass Publishers.

Drummond, H. (2001). The art of decision making, Mirrors of imagination, masks of fate. Chichester: Wiley.

Fletcher, C. (1997). The future of psychometric assessment: fostering positive candidate attitude and reactions. Selection Development Review, 13, 8-11.

Freyd, M. (1923). Measurement in vocational selection: an outline of research procedure. Journal of Personnel Psychology, 2, 215-249.

Greuter, M. A. M., \& Algera, J. A. (1989). Criterion development and job analysis. In P. Herriot (Ed.), Assessment and selection in organizations. New York: John Wiley.

Guion, R. M. (1965). Personnel testing. New York: McGraw-Hill Book Company.

Guion, R. M. (1997). Criterion measures and the criterion dilemma. In N. Anderson, \& P. Herriot (Eds.), International handbook of selection and assessment (pp. 1-38). England: Wiley.

Hastie, R. \& Park, B. (1986). The relationship between memory and judgement depends on whether the judgement task is memory-based or on-line. Psychological Review, 93, 258-268.

Howard, A. (1995). Rethinking the psychology of work. In A. Howard (Ed.), The changing nature of work. San Francisco: Jossey-Bass.

Janis, I. L. (1972). Victims of groupthink. Boston, Mass.: Houghton Mifflin.

Khun, T. (1962). The structure of scientific revolutions. Chicago: University of Chicago Press.

Leyens, J-P. (1983). Sommes-nous tous des psychologues? Approche psychosociale des theories implicites de personnalité. Bruxelas: Mardaga. 
Leyens, J-P. \& Dardenne, B. (1996). Basic concepts and approaches in social cognition. In M. Hewstone, W. Stroebe, M. Stephenson \& M. Geoffrey (Eds.), Introduction to social psychology (2nd Edition). Oxford: Blackwell Publishers.

Leyens, J-P. \& Yzerbyt, V. (1997). Psicologia social. Lisboa: Edições 70.

Lindblom, C.E. (1959). The science of 'muddling through'. Public Administration Review, 19, 79-88.

Lord, R. G. \& Maher, K. J. (1990). Alternative information processing models and their implications for theory, research and practice. Academy of Management Review, 15, 9-28.

Macan, T. H. \& Dipboye, R. L. (1988). The effects of interviewers initial impressions on information gathering. Organizational Behavior and Human Decision Process, 42, 364-387.

Mandler, G. (1989). Memory: conscious and unconcious. In P. R. Solomon, G. R. Goethals, C. M. Kelley \& B. R. Stephens (Eds.), Memory: interdisciplinary approaches. New York: Springer-Verlag.

March, J. G. \& Olsen, J. P. (Eds.) (1976). Ambiguity and choice in organizations. Bergen: Universitetsforlaget.

Matarazzo, J. (1992). Psychological testing and assessment in the $21^{\text {st }}$ century. American Psychologist, 47, 1007-1018.

Matte-Blanco (1975). The unconscious as infinite sets. London: Duckworth.

Matte-Blanco (1988). Thinking, Feeling and being. London: Routledge.

Millar, R., Crute, V. \& Hargie, O. (1993). Professional interviewing. London: Routledge.

Mintzberg, H., Raisinghani, D. \& Theoret, A. (1976). The Structure of unstructured decision processes. Administrative Science Quarterly, 21, 246-275.

Newell, S. \& Shackleton, V. (2001). Selection and assessment as an interactive decision-action process. In T. Redman \& A. Wilkinson (Eds.), Contemporary and human resource management. Harlow, England: Financial Times, Prentice-Hall.

Nisbett, R. E. \& Ross, L. (1980). Human inference: strategies and shortcomings of social judgment. Enlewood-Cliffs, NJ: Prentice-Hall.

Proença, T. \& Oliveira, E. (2005). From normative to tacit knowledge: the analysis of CV job candidates in personnel selection. Proceedings of the $6^{\text {th }}$ International Conference on Organizational Learning and Knowledge. University of Trento. Italy.

Oliveira, T. C. (1998). A Socio-cognitive analysis of panel interviewing. A dissertation for the degree of Doctor of Philosophy. University of London.

Pfeffer, J. (1981). Power in organizations. Marshfield, MA: Pittman.

Polanyi (1958). Tacit knowing: it's bearing in some problems of philosophy. Review of Modern Physics, 34, 601-616.

Polanyi (1962). Personal knowledge. Chicago: University of Chicago Press.

Postman, L., Bruner, J. \& McGinnies, E. (1948). Personal values as selective factors in perception. Journal of Abnormal and Social Psychology, 43, 142-154. 
Ribeiro, R. B. (1996). Selecção de pessoal: métodos e aplicações. In C. A. Marques, \& M. P. Cunha (Eds.), Comportamento organizacional e gestão de empresas. Lisboa: Publicações D. Quixote.

Robertson, I. T. \& Smith, M. (1993). Personnel selection methods. In M. Smith, \& I. Robertson (Eds.). Advances in selection and assessment. Chichester: John Wiley \& Sons.

Rose, N. (1990). Governing the soul: the shaping of private self. London: Routledge.

Schneider, B. (1994). Selection for service business. 23. ${ }^{\circ}$ Congresso Internacional de Psicologia Aplicada, 17-22 Julho, Madrid.

Simon, H. A. (1978). Rationality as process and product of thought. Journal of the American Economic Association, 68, 1-16.

Simon, H. A. (1987). Making management decisions: the role of intuition and emotion. Academy of Management Executive, 1, 57-64.

Smith, M. \& Robertson, I. (1993) (Eds.). Advances in selection and assessment. Chichester: John Wiley \& Sons.

Townley, B. (1994). Reframing human resources management: power, ethics and the subject at work. London: Sage Publications.

Tversky \& Kahneman, (1988). Rational choice and the framing of decisions. In D. E. Bell, H. Raiffa \& A. Tversky, (Eds.), Decision Making: descriptive, normative and perspective interaction. Cambridge: Cambridge University Press.

Visser, C. F., Altink, W. M. M. \& Algera, J. A. (1997). From job analysis to work profiling: do traditional procedures still apply? In N. Anderson \& P. Herriot (Eds.), International handbook of selection and assessment (pp. 393-412). England: Wiley.

Wanous, J. (1992). Organizational entry: recruitment, selection, orientation and socialization of newcomers. New York: Addison-Wesley Publishing Company.

Wareign, R. \& Stockdale, J. (1987). Decision making in the employment interview: an empirical study. Personnel Review, 16, 4-26.

Webster, E. C. (1964). Decision making in the employment interview. Quebec: Eagle Publishing Co. Ltd.

Werninont, P. F. \& Campbell, J. P. (1968). Signs, samples and criteria. Journal of Applied Psychology, 52, 372-376.

Wiener, N. (1954). The human use of human beings. Boston: Houghton Miffin.

Wittgenstein (1982). Remarks on the philosophy of psychology. Oxford: Basel Blackwell.

Womack, J. P., Jones, D. T. \& Roots, D. (1990). The machine that changed the world. New York: Macmillan Publishing Company. 